\title{
mStories: exploring semiotics and praxis of user generated mobile stories
}

Jessica K. Frawley (Corresponding author)

School of Software, Faculty of Engineering and IT, University of Technology Sydney, Sydney, Australia

UTS, P.O. Box 123. Broadway NSW 2007

E: Jessica.Frawley@uts.edu.au

M: +61 403-877-430

Jessica Frawley is founder of $m$ Stories and a doctoral candidate at the University of Technology Sydney. Her research focuses on the relationship between mobile technology and users' approaches to meaning making.

Laurel E. Dyson

School of Software, Faculty of Engineering and IT, University of Technology Sydney, Sydney, Australia

UTS, PO Box 123, Broadway NSW 2007, Australia

E: Laurel.E.Dyson@uts.edu.au

$\mathrm{T}:+61295144493$

Laurel Dyson is a senior lecturer at UTS's School of Software and president of the Australian and New Zealand Mobile Learning Group (anzMLearn). Her research focuses on mobile learning and the use of mobile technologies in Indigenous communities.

Manuscript word count: 7,987 


\section{mStories: exploring semiotics and praxis of user generated mobile stories}

Innovations in information and communication technologies (ICT) have allowed people to actively author multimodal content and engage in new meaning-making practices. New Literacies research has gone some way to understanding new meaning-making behaviours. However, such research often derives its understandings from studies undertaken within formal educational settings. Mobile technologies are increasingly situated outside such domains, and the informal use of these devices by adults, remains on the periphery of scholarly focus. mStories is a creative participatory mobile storytelling project, comprised of nine adult participants from across Australia and the UK. Taking a multidimensional perspective, this study explores both semiotics and praxis involved in the creation a single mStory. A semiotic analysis of a single mStory found that the user-generated content demonstrated complex and sophisticated multimodal sense relations. However, control over the textual or compositional metafunction of the text was determined largely by the computer interface, with users habituated to relinquishing authorial control over this element. Within this study mobile literacy praxis was characteristically ad hoc and contextually embedded, and though mobile technology invites such practices, users were neither determined nor limited by this, and happily turned to other devices where necessary.

Keywords: multimodal literacy; mobile technology; user praxis; semiotics; usergenerated content.

\section{Introduction}

Developments and innovations in ICT have led to marked changes within the communication landscape, most recently through the ubiquity of mobile devices. Within the spectrum of mobile computing, smartphone ownership has been increasing rapidly worldwide since 2009 (Llamas and Stofega 2010). By 2012 Australia saw not only an increase in smartphone ownership but an increase in people using such devices for purposes other than texting and calling (Mackay 2012). The convergence of multiple 
functions into the single smartphone device has enabled people to communicate via a range of modes and medias, including spoken voice, SMS, email, photographs, video, sound files, and various combinations of these.

Though technology does not determine human behaviour, mobile devices, and their supporting ICT ecology (see Brady and Dyson 2010), afford people with the tools and platforms through which to read, write, edit, and share multimedia content. Within such socio-technical conditions the supremacy of written communication is challenged. The communication culture shifts from one that is logocentric to one that is ocularcentric (Spencer 2011) and the semiotic landscape comes to be characterised as increasingly visual and multimodal (Kress 2003). Definitions of literacy are no longer solely confined to the reading and writing of lexicographic texts, which are themselves redefined as multimodal activities (Jewitt 2005; Kress 2003). Whilst adults engage in new meaning making practices, their informally acquired literacy skills and semiotic products have remained largely peripheral within the academic discussion.

This article presents $m$ Stories, a participatory creative mobile storytelling project, the analysis of which extends existing scholarly conversation on multimodal literacy to adults within informal, and increasingly mobile, contexts. Comprised of nine adults from Australia and the UK, mStories participants created their "stories" using various modes and medias on a range of smartphones. The stories were showcased collectively on the mStories website (Figure 1.) ${ }^{1}$. Recognising that understandings of literacy must account for not only the product but the process that people undertake (Andrews and Smith 2011), and that an understanding of what people make ought to be linked to what people do (Kress 2003), this study takes a multidimensional approach

\footnotetext{
${ }^{1}$ http://mstories.squarespace.com/
} 
and explores: 1) what is made and 2) how it is made, within the context of the mStories project.

This article begins by situating the mStories study within the context of existing New Literacies research and literature. The paper provides an overview of the mStories project and the research methods used. Taking a multidimensional perspective this article explores the semiotics and human praxis associated with one mStory. The $\mathrm{mStory}$ is analysed using an intersemiotic analytic framework and human practice is explored through interview. We conclude with an overview of the research and suggest avenues for further academic discussion.

\section{Background}

Accepting that the range of human communication and interaction involves multiple modes is uncontroversial (Stivers and Sidnell 2005). However, it is perhaps only recently that systematic research has begun to explicitly frame and conceptualise such phenomena in terms of literacy. Innovations in ICT have emphasised new forms of "text" production that include sound, still and moving image. For whilst visual artefacts have existed prior to the advent of photography and film, producing and transmitting such content was largely confined to the domain of the expert or specialist. New technologies have enabled individuals to engage in new authoring behaviours. This is especially the case with mobile devices, which have opened up new multimedia authoring practices to the layperson through converging many functions within the one device: twenty years on and cameras, microphones, video and voice recorders, all "fit in your pocket" (Figure 2.) (TECHi 2012).

In such a socio-technical environment much of our encoded language and texts are being reconceptualised as multimodal (e.g. Bearne 2005; Clark and Mayer 2003; Jewitt 2006; Kress 1997; Pailliotet and Mosenthal 2000; Reinking et al. 1998). The 
field of New Literacies research, though still very much in its infancy, has begun to expand the discussion of literacy beyond the scope of printed text to encompass new digital multimedia artefacts. As new technologies increasingly become vehicles for these new literacy practices and semiotic products, the nexus between technology and literacy has emerged as an important area for research (Mills 2010a).

As conceptions of literacy expand to encompass multimodal communicative resources, the acquisition of such skills and habits has become a fertile field for exploration. There has been a burgeoning of scholarly interest in how we conceptualise and make sense of this landscape. Multimodal discourse analysis and social semiotic approaches have contributed frameworks for understanding discreet modal resources such as visual images (Kress and van Leeuwen 2006), typography (van Leeuwen 2005), music (van Leeuwen 1999), art (O'Toole 1994), action (Martinec 1998) and film and television (Iedema 2001). Furthermore, intersemiotic approaches (Liu and O'Halloran 2009; Royce 1998; 2007; Unsworth 2006; 2008a) provide a means for thinking about how multiple modes relate to each other to form a coherent semantic unit. In addition to semiotic approaches, there has been a turn towards focusing on practice (Couldry 2004). The field of New Literacies has contributed significantly to understanding how new practices are conceptualized, adopted and learnt (e.g. Coiro et al. 2008; Greenhow and Robelia 2009; Knobel and Lankshear 2007; Kress 2003; Lankshear and Bigum 1999; Lankshear and Knobel 2006; 2008; Leu et al. 2007; Livingstone et al. 2008; Matthewman et al. 2004; Unsworth 2008a; b). Today, conferences (e.g. International Conference on Multimodality), journals (e.g. Visual Communication, Social Semiotics, Semiotica) and labs (e.g. the National University of Singapore's Multimodal Analysis Lab, USC's New Literacies Project) have emerged as spaces for multidisciplinary discussion around the semiotics and practice that come with new media. 
Perhaps unsurprisingly, in finding its disciplinary identity, the field has brought with it intellectual and methodological traditions from several areas (Livingstone et al. 2008). However, despite a vast heterogeneity of analytic approaches, with disciplinary traditions also comes disciplinary bias. Semiotic and intersemiotic analysis, with few exceptions (Pachler et al. 2010b; van Leeuwen et al. 2012), continue to be largely applied to expert generated content. Similarly, empirical studies of literacy behaviour and practice, have thus far largely focused on the formal educational settings, whether in primary (Fails et al. 2010; Wolfe and Flewitt 2010), secondary (Jewitt 2005; Mills 2010b) or higher-education (Spalter and van Dam 2008) groups. Though these studies acknowledge the out-of-school learning and practice of their students, they invariably return to the institutional environment.

However, multimodal content is no longer generated exclusively by experts and nor are the corresponding literacy practices only of relevance to those enrolled in formal education. User-generated platforms have created a widespread participatory culture in which non-experts create and share new content online (Jenkins et al. 2009). An understanding of digital technologies and multimodal literacy practices are perceived to be important for participating in a society that utilises both (Mills 2010a). To understand new literacies we need to look at how such skills are acquired, adopted, and embedded into the lives of people who may be currently outside the current research focus.

Though not limited to the mobile device, a significant amount of this content is produced and consumed via mobile device. Though early generations of "text-and-call" mobile phone technology fell neatly into the domain of traditional literacy and linguistic discourse (e.g. Crystal 2008), new generations of smartphone afford communication that is very much outside of this domain. Mobile devices, such as smartphones, enable 
everyone to produce and communicate text, image, audio, video and multimedia culture and meanings. Whether literacy is to be limited to reading and writing, or extended to account for other modes it is clear that traditional logocentric concepts of literacy remain inadequate for understanding either the practice or the semiotic products enabled by people and these mobile devices.

As worldwide smartphone ownership continues to increase there is much to be gained from extending multiliteracies research to the mobile space and users' mobile practice. New literacies are typically described as both dynamic and situationally specific (Coiro et al. 2008; Hull and Nelson 2005; Kress 2003; Lankshear and Knobel 2006). As such, we need to ask questions about the impact of a mobile culture where the context in which we create things continually changes. Foundational research has to be careful to avoid focusing solely on the device and technology. Instead, socio-cultural conceptualisations that acknowledge how such technology might be appropriated and embedded within the lifeworld of their users (Pachler et al. 2013; Pachler et al. 2010a) permit the researcher a grounding that avoids the pitfalls of technological determinism or fetishisation. As mobile devices afford users new ways in which to navigate through an increasingly visual semiotic landscape it is important that understandings of new literacies phenomena include the adult user, their informal learning and the mobile space.

\section{The mStories project}

mStories was a participatory creative research project, established to empower writers and non-writers to engage in new modes of creative practice. As such mStories is both public writing project and New Literacies research project. Whilst research into literacies of user-generated content has been done (e.g. Davies 2012; Greenhow and Robelia 2009; Spires and Morris 2008) we wanted to explore how users go about 
forming new practices outside of existing technical platforms which have already established their own genres and stylistic conventions (e.g. Facebook, YouTube, Flickr). The rate of technological change means that, in addition to understanding existing practice, it is also important to explore the potentialities and possibilities of future practice. This is especially the case in mobile user-generated content, where technical convergence lends itself to users creating multiple medias at any given time. The mStories website was developed to host the stories that people wanted to tell and allowed video, image, sound, text and combinations of these. By providing users with a degree of creative freedom mStories was better able to explore how users go about forming new literacy habits and practices. Creative perspectives have been shown to be a valuable approach to researching multimodal semiotics and practice (e.g. van Leeuwen et al. 2012). Though pioneering work on digital storytelling has demonstrated the empowerment that such approaches can have (Lambert 2002; Meadows 2003) these are largely under theorised and typically not framed in terms of literacy.

Focusing on mobile creative practice, mStories participants created short "stories" using their mobile phone device. Stories could be fiction, non-fiction, or in any form that participants chose. Similarly, stories could be produced using any feature, function or combination of functions on the participant's mobile phone device. Writers groups were initially targeted, and the research designed around a meeting-based approach. However, the nature of mobile practice and the mStories project changed both the composition of the group and the mode of participation. Though writers groups were initially targeted, the final group contained only three participants who were actively engaged in creative writing, either professionally or in their spare time. Other participants joined through informal channels, such as word of mouth, social networks, and via other participants. Also participants opted for digital forms of participation, 
such as phone calls, emails, SMS, and Skype videoconferencing, rather than the face-toface meetings initially envisaged. With mobile participation came a change to both the participatory model and a preference for individual, idiosyncratic storytelling choices. The final $m$ Stories project group was composed, in total, of nine people with ages spanning from the 21-25 age bracket to the 46-55 age bracket: five were from Australia and four from the UK; four were male, and five were female.

\section{Research methods}

Following from the argument that understandings of literacy must encompass both what is made and how it is made (Andrews and Smith 2011; Kress 2003), recent studies have started to adopt multidimensional approaches (e.g. Alyousef 2013). There are good reasons for taking different methodological and analytic approaches when attempting to understand a particular phenomena. We adopt what Richardson (2000) refers to as crystallisation, which, eschewing positivist research paradigms associated with triangulation, offers an approach that accounts for the position of the researcher and the potentially mutable and evolving nature of the subject of interest. With this philosophy in mind, the wider mStories project adopted surveys, intersemiotic analysis, and semistructured interviews. Rather than give scant coverage to all aspects of the project, this article focuses in-depth on a single instance within the project. Detailing an intersemiotic analysis of one story and an exploratory interview with its author, Zena Shapter, we can tell an individual, but indicative, story of literacy from both semiotic and praxeological perspectives. The semiotic analysis explores what was made, whilst the interview explores what people do.

\section{What was made: semiotics and intersemiotics of the mStory}

The final website contained a diverse range of mStories. Participants engaged in poetry, 
photo and video diaries, and individual videos or images that captured a single moment or instance. Not only was the concept of a "story" reinterpreted but so too was the modes and medias used. All mStories engaged with the reader through either still or moving image, reflecting the largely visual semiotic landscape of the World Wide Web. Furthermore, the majority of participants chose to support their image/s with words. Shapter's story, a combination of still image and text, was selected as one representation of this.

\section{Zena Shapter's mStory: “The Voice”}

"The Voice" (Figure 3.) is an mStory written by Zena Shapter, a published author. Written on an iPhone 4S the story is comprised of five images and associated paragraphs of written text. The visual analysis will refer to the images sequentially as: "IMAGE 1: Children's playground"; "IMAGE 2: The street"; "IMAGE 3: The classroom"; "IMAGE 4: The jogger"; and "IMAGE 5: The home and television".

Royce's $(1998 ; 2007)$ foundational intersemiotic complementarity framework was selected to analyse this story. Grounded in Hallidayan Systemic Functional Linguistics (SFS) (see Halliday 1978; 1985), this framework analyses the visual first, using visual grammar (see Kress and van Leeuwen 2006), and lexicogrammatic elements second. Lastly, visual and written elements are explored for how each relates to the other: their level of "intersemiosis". In a multidimensional study this has the advantage of capturing two perspectives within a single, and efficient, analytic framework: firstly, through analysis of the visual and the written as two independent components, and secondly, through analysis that explore how each mode relates, or fails to relate, to the other. Royce's (1998) framework uses a tabular format for identifying multimodal sense relations in the Hallidayan ideational metafunction. For the purposes of this article two exemplar tables are included, whilst the three remaining tables are 
summarised and discussed within the text. Likewise whilst sentence numbers were used in the original tabular analysis, examples will be highlighted with quotations ${ }^{2}$. As per standard SFS approaches this discussion will focus on the three Hallidayan metafunctions: the ideational, the interpersonal and the compositional.

\section{Ideational: What is it about?}

Adopting a naturalistic coding the analysis explored who or what was represented, the circumstances in which the subject was situated and the qualities and attributes assigned to what is represented. Royce (1998) argues that there are various lexico-semantic ways in which intersemiotic complementarity can be achieved within the ideational metafunction principally:

- Repetition (R): identical experiential meaning

- Synonymy (S): the same or similar experiential meaning

- Antonymy (A): opposite experiential meaning

- Meronymy (M): the relation between the part and whole of something

- Hyponymy $(\mathrm{H})$ : the relation between a general class of something and its subclasses

- Collocation (C): an expectancy or high probability to co-occur in a field or subject area

Shapter's story featured all of these intersemiotic sense relations, with the degree of intersemiotic complementarity varying slightly across images and their spatially corelated text on the web page. Examples of weaker and stronger ideational image-text

2 For all five tables of the ideational intersemiotic analysis please contact the corresponding author. 
intersemiosis are discussed.

Weaker intersemiosis

Intersemiosis between image and text is comparatively weaker in IMAGE 1 and 3 and their respective paragraphs. As an example, in IMAGE 1 (Table. 1), the visual subject of "The Playground" relates to the written text through repetition of the noun "playground" and also in meronymy with the words "bridge" and "slippery dip". Since the theme of the story is "spooky", most processes articulated in the text relate to IMAGE 1 antonymously. This antonymous jarring between text and image is effective within the speculative-fiction genre that the story inhabits. However, the circumstances of the scene - the time of day, the trees surrounding the playground - have no verbal referent.

Stronger intersemiosis

Intersemiosis is, arguably, strongest between IMAGES 2, 4, and 5 and their texts. Comparatively IMAGE 2 (Table 2.) and its respective paragraph features intersemiosis between all verbal and visual elements: participants, processes, goals, circumstances, and attributes.

Though some image-text passages talk to each other more readily, there is still an overall coherence between text and image throughout the ideational meanings of the story.

Interpersonal: How does it enact the social?

Analysis of the interpersonal metafunction demonstrated increasingly sophisticated methods of intersemiosis used throughout the story. Indeed, it can be argued that much 
of the power of this particular story hangs on how the image and text enact a relationship with the reader or viewer. This analysis discusses the interpersonal meanings of "The Voice" in its representations of: visual address, level of involvement, power relations, social distance and visual modality.

Visual address

Within all five images there is an absence of a direct gaze, or vector, connecting what is represented within the frame of the image with the viewer and viewing plane. Such images are considered offers of information, that is, nothing within the image demands a specific response from the viewer, such as a response to a question, or a rejection or acceptance of a command (Kress and van Leeuwen 2006). Such visual offers are reinforced through the written story elements: statements and rhetorical questions.

Level of involvement

The viewer's level of involvement is carried by the horizontal angle. This angle indicates the level of detachment or involvement enacted between what is represented and the viewer (Kress and van Leeuwen 2006). With the exception of IMAGE 1, which is shot 'head on', all the images within the mStory have either slight or extreme oblique angles between the viewer and the represented subject within the image. Though the use of the oblique angle normally positions the viewer as an outsider in the depicted scene, the verbal text contextualises this interpretation. In IMAGE 2, the angle from which the image is taken is that of the character within the text: the reader becomes the mother looking for her children. Similarly, the extreme oblique angles used in IMAGE 4 and IMAGE 5, when combined with the framing of the shot and the written text, position the viewer as the malevolent voice that creeps up on the characters within the story. In 
this way, though the oblique horizontal angle can be used to detach a viewer from the scene within this story, it is effective at emphasising the perspective of the hidden character that dominates the story.

Power relations

Power relations enacted between viewer and image change throughout the five images from a neutral vertical angle (IMAGE 1 and IMAGE 2) to steep vertical angles that position the viewer as looking down upon the scene that is represented (Figure 4.). The interpretations of these vertical angles are dependent on what is represented in the photograph. So whilst IMAGE 3 positions the viewer as looking down on the classroom, this vertical angle is less a mark of power relations than a design that positions the viewer as an adult within the children's classroom. Had the shot been taken from a lower vantage point, with an upwards angle, the viewer would be positioned as a child instead. However, whilst the power relations and constructed viewer identity within IMAGE 1, 2 and 3 are fairly neutral, IMAGE 4 and IMAGE 5 dramatically shift the enacted power-relations. In IMAGE 4 and IMAGE 5 the angle that the shot is taken from positions the viewer in an increased power position, in which they look down onto the represented participants, a jogger and TV watcher. In these two images the viewer is not visually identifying with the represented participant, but as the sinister voice that has grown more powerful and personal within the story.

Social distance

The framing of an image suggests how close the viewer is to what is represented: closeups may enact close social proximity, and long shots may enact greater social distance (Kress and van Leeuwen 2006). Within "The Voice" the images take the viewer on a 
journey from a distanced, impersonal relationship with what is represented, to an intimate proximity in the final image (Figure 5.). The change in visually enacted proximity accompanies text that begins by referring to "they" and culminates in referring directly to "you" the reader. Whilst not explicit in the written text, IMAGE 4 and IMAGE 5 position the viewer as the sinister voice that inhabits the story. The narrative told by the visual image sequence is suggestive. In many ways these images provide clues to answering the question in the final sentence: "for alone that night you'll know who I am". The answer to the question "who" is suggested by the images: you are the voice. That this is not explicit within the text enables the story to retain the mystery of indeterminacy that the oblique angles of the images convey.

\section{Visual modality}

Like written language, images have a visual modality that relates to the truth, credibility and probability of what they present to the viewer. Within "The Voice" the use of photography may act as a representation of reality that has a high modality in its representation of truth. The modality of photography may be described as more authentic than that of cartoon, sketch or caricature. The naturalism of the images presents a representation of reality that (with the exception of one black and white image) provides similar modality markers to those within the text: "it will", "they will", and "you will". There is only one modality marker that contravenes this and that is the use of the marker "might". With this exception, intersemiotic complementarity of the interpersonal is achieved through the modalities of both the visual and the lexicogrammatic elements of the text. 
Compositional: How is it put together as a semiotic construct?

The compositional aspects of a multimodal text indicate how the layout of image and text affects the meaning of what is depicted. In comparison to the high degree of complementarity displayed through ideational and interpersonal metafunctions, intersemioisis was less pronounced within the compositional. Compositional meanings are inseparable from the conventions and genre of the text: in this case the web page (Figure. 6). Royce (2007) identifies information value on the page, salience and degrees of framing on the page, and reading paths as key visual and verbal components necessary in identifying complementarity.

Information valuation

In reading the compositional we cannot separate the individual story from the wider context of the mStories website, which itself may be viewed on different screens of different devices. The value of the information in the mStory includes surrounding features such as the website banner, navigation bar and menu that locate the story hierarchically as a part of a wider site (Figure. 6). In addition to the wider compositional meaning-making elements, the mStory has internal information valuation consistent with reading conventions of web pages; the text is presented as a single column that takes the reader from top (beginning) to bottom (end) of the story, the images mirror this. In this way placement gives the information a chronological value of earlier and later, first and last.

Salience

Salience refers to the relative sizes of the visuals compared to the verbal aspect of the text on the page. In this story, image is secondary in size and status to written text. This 
arguably reduces the intersemiotic complementarity within the text.

\section{Degrees of framing}

As photographs, each image within the text is framed off from the text that surrounds it. A semiotic reading would say that there is a linear division between the text and the images within the story. The image and text do not compete for the same space as framing cuts one off from the other.

Potential reading paths

A specific reading path is established by text that would, given the language and the sentence layout, be read from left to right. Though the images do not always contain vectors that internally mirror this left to right direction, the placement of the images and their co-spatiality with the text, indicates to the reader which image relates to which piece of text.

This analysis of Shapter's story demonstrates that existing methods of multimodal discourse analysis can be gainfully applied to user-generated texts. What this shows is that Shapter was capable of using technology in a new way to create content with highly complex and sophisticated forms of intersemiosis.

\section{What people do: the praxis of creating an mStory}

Following the intersemiotic analysis of "The Voice", Zena Shapter was interviewed on the experience of creating her mStory. The interview was semi-structured and exploratory, with the aim to investigate human praxis. Analysed for themes, the findings were then validated by the respondent, Zena Shapter. Themes were identified as being descriptive of the author's mStories practice: 
- $\quad$ Situated and locative

- Individually motivated

- Emergent and transformative

- Author designed

- Compositionally limited

\section{Situated and locative}

In contrast to other ICTs, one of the defining features of the mobile device is its portability (Laurillard 2010; Pachler 2010): “mobile technology is substantially different from desktop computing in its essential connection to mobility and the contexts in which it is used" (Kukulska-Hulme 2010, p. 11). Shapter used an iPhone 4 and, composed her mobile story using the phone camera and written SMS. Shapter compares the use of this technology to her typical writing practice:

On the computer at home I would have a research document, drafts, I would find photos on the Internet that would inspire me, and I would put it all in a folder and then have multiple things open at the same time. You can't do that on a phone, so I had to produce something completely different.

Arguably facilitated by both the constraints and affordances of the mobile device Shapter's mStory process differs from her usual planned writing activity. Indeed it can be seen as almost a reversal of her desktop practice. Instead, action and location become a catalyst for reflection, and story creation. The entire story begins with action in situ and the mobility of the device enables time and place to become generative elements within an experiential process. Decisions about the story are made in the moment, with the location frequently providing creative impetus: 
So I was sat in the playground, the kids were off playing. And then all of a sudden all of the children were behind me, not in front of me, then that's when I got my camera [phone] out and took the first picture of the playground with no kids in it. There were plenty of kids behind me and all out of view, and it looked a bit spooky, and a bit kind of quiet, I snapped the picture, then I thought 'my story's going to be a spooky story'.

Shapter describes this process as a largely exploratory one, of having to "find an idea and write something, not knowing where it was going to go". In contrast to her usual planned activity she describes the nature of the mobile device requiring her to "be a bit of a pantser" [sic]: to write "by the seat of your pants". The technology affords practices that are less planned, and are more immediate, exploratory and ad hoc in nature.

\section{Individually motivated}

The technology's affordances and constraints are factors that shape Shapter's mobile practice, however this practice is not technologically determined and the author's individual agency is not diminished. Recurrent throughout the interview was the theme of authorial intent and individual motivation. From the outset of the project Shapter knew that her story was going to be fictional since, for her, "a story is a work of fiction". Further to this, Shapter further defined her story to the genre of speculative fiction. As a writer of speculative fiction, she chose to use the device to explore things that were of interest to her specifically.

\section{Emergent and transformative}

Whilst the surrounding context are used by the author as generative elements in the story writing process, Shapter frequently transforms what she sees to fit with her designs and motivations for the story. Initially, Shapter describes her first images as instantaneous, and opportunistic; For example, in IMAGE 2: "A guy passed them and 
looked at them a bit funny... and I was like 'ooh I'll get that'". However, as the story emerged and gained its own identity, the author began to design visual products that would align with her intended story and meaning.

\section{Author designed}

To support an emerging story Shapter makes numerous decisions and choices in relation to both the mode used and how she uses this.

The story could stand alone without the pictures, but I wanted to involve the reader on two levels. This is the opportunity here to involve them in a way that you can't do traditionally, [...] you can do it via words and photos- so they complemented each other through different layers.

Whilst Shapter articulates that the story "could" stand alone without the images, she nevertheless makes a decision to use photographs. User difficulties in writing with the small mobile interface are sometimes overcome through audio and image features (Coulby et al. 2011; Vavoula et al. 2009), however, in this instance the use of image is not for ease of use, but to serve a specific communicative purpose and authorial intention.

Shapter was able to articulate a lot of the design decisions that she made, especially those relating to the decisions that she made in the moment:

The one in front of the TV I had to angle it because I wanted to show a bit of head, the wine glass and a bit of the TV. The jogging photo I wanted it to look spooky, spooky and uninviting and then the same as the pre-school one, which had to look spooky, but it's a very cheery classroom. So yes, I did with those three photos [IMAGE 3, IMAGE 4, IMAGE 5] deliberately pick angles to exclude things that would have conflicted with my story.

In addition, to deliberately creating visuals to support her story, the participant was also 
readily able to discuss verbal elements. The author deliberately chose the first person voice as a means of getting "straight inside the character that is speaking and talk to the readers". However, though Shapter was conscious of using written words to enact the social relationships she was not "consciously aware" of the extent to which some of the overall visual design supported this. During the interview process the interviewee asked the researcher: "you read it...what did you think?"; The researcher explained her personal reaction and Shapter responded:

Subconsciously you're right, the photos they kind of get closer and closer don't they? So, outside and we're quite a distance away, then we're getting more intimate, and then we're close but that [second to last image] at a sort of a leg, you know and that [last image] near someone's head [...] yes it succeeds better than I thought.

This dialogue demonstrates that though author was able to create visuals that worked intersemiotically to support the verbal meanings, she sometimes lacked the language to articulate the visual design decisions made. This aligns with recent research on informally acquired design literacy, where people acquire skills somewhat intuitively but lack the language to describe what they did or why (Sheridan and Roswell 2010).

\section{Compositionally limited}

The project found that all participants had to use another device for creating the compositional aspect of meaning in their texts. The participant described having a very specific idea of how she wanted to compose the final mStory: "I had a very clear image in my mind of how I wanted to lay it out". The author of "The Voice", Zena Shapter, composed the final layout of the story herself. However whilst content was composed and collected on her iPhone 4, there was no tool to enable her to structure this into a coherent whole in the way she wanted, and the compositional meanings were generated 
by desktop computer, not a mobile device (Figure 7.). What emerges throughout the interview is that whilst the participant was able to create ideational and interpersonal components of the story with her phone, the compositional element had to be undertaken with a computer. Perhaps more interesting than the compositional limitations placed on people by one particular system, whatever that may be, is the extent to which participants within the project accept such limitations, and either accept the compositional authorship of the system or happily default to other devices through which to realize their authorial intent.

Mobile practice and the creation of new literacy content is characterised as one that is situated, locative and experiential in nature. Additionally, whilst the focus of the project was on mobile literacy practice, it was to be neither possible, nor desirable, to separate mobile practices from what Brady and Dyson (2010) refer to as the ICT ecology. Such an ICT ecology is specific to an economic and cultural climate in which participants can afford more than one device, and are habituated to doing so. What the mobile device did afford was an immediacy that catalytically triggered further meaning-making activities. This study emphasises the degree to which users surrender authorial control over compositional meaning to the system that they are in, or alternatively find ways to navigate around this outside of that system. We conceptualise mobile literacy as less about the mobile device and more about the mobile complex and wider ICT ecology (Pachler et al. 2010a).

\section{Conclusions}

As the semiotic landscape changes, mobile technology affords ways for people to navigate through this landscape as both consumer and producer. The field of New Literacies research has contributed significantly to the reshaping and redefining of 
literacy. Within the changing parameters of this discipline, the practices of the "digital native" and child user have dominated. To date, existing definitions and understandings have overlooked the adult user, the informal learning space and the mobile technologies that inhabit such spaces. Reflecting a wider societal shift from a "logocentric" to an "ocularcentric" culture and the visual semiotic landscape (Kress 2003; Spencer 2011) all $m$ Stories participants engaged with the visual mode principally through the use of still or moving image captured using their mobile device.

For a concept of new literacy to be inclusive, it has to step outside of the classroom and engage with people and the devices that they use. The mStories project addresses this through a creative participatory project that includes adults in the process of defining new literacies. We have taken a semiotic and a praxeological approach through which to explore this phenomenon. This picture, like all pictures, is not independent of the angles, framing and context that generated it. As such, this paper aims to open up discussion about how we conceptualise mobile practice.

Though all the adult users were not always able to articulate the design decisions behind their action, their semiotic products and practice demonstrated clear design intentions. However, whilst people remain largely in charge of the ideational and interpersonal meanings within their text, their degree of control over the compositional/textual function is often determined by a system outside of their control, for example a web site or content-sharing platform. Despite the limitations of the mobile device, Shapter and other participants fulfilled their design intentions by turning to a range of different ICTs. In this way we may start to see the mobile device as catalyst to further practice. 


\section{Acknowledgments}

The authors would like to thank all of the mStories participants. We would especially like to thank Zena Shapter for allowing us to print and analyse her mStory, "The Voice", as part of this research.

\section{References}

Alyousef, H.S. 2013. An investigation of postgraduate business students' multimodal literacy and numeracy practices in finance: A multidimensional exploration. Social Semiotics 23, no 1: 18-46.

Andrews, R. and A. Smith. 2011. Developing writers: Teaching and learning in the digital age. Maidenhead, Berkshire: Open University Press.

Bearne, E. 2005. Interview with Gunther Kress. Discourse: Studies in the Cultural Politics of Education 26, no 3: 287-99.

Brady, F. and L.E. Dyson. 2010. A comparative study of mobile technology adoption in remote australia. In Seventh International Conference on Cultural Attitudes towards Technology and Communication (CATaC, eds Sudweeks, F, Hrachovec, $\mathrm{H}$ and Ess, C, 69-83. Vancouver, Canada: Murdoch University, Australia.

Clark, R.C. and R.E. Mayer. 2003. E-learning and the science of instruction : Proven guidelines for consumers and designers of multimedia learning. San Francisco, CA: Jossey-Bass Publishers.

Coiro, J., M. Knobel, C. Lankshear and D. Leu. 2008. Central issues in new literacies and new literacies research. In Handbook of research on new literacies, eds Coiro, J, Knobel, M, Lankshear, C and Leu, D, 1-21. New York: Lawrence Erlbaum Associates.

Coulby, C., S. Hennessey, N. Davies and R. Fuller. 2011. The use of mobile technology for work-based assessment: The student experience. British Journal of Educational Technology 42, no 2: 251-65.

Couldry, N. 2004. Theorising media as practice. Social Semiotics 14, no 2: 115-32.

Crystal, D. 2008. Txtng: The gr8 db8. Oxford: Oxford University Press.

Davies, J. 2012. Facework on facebook as a new literacy practice. Computers \& Education 59: 19-29. 
Denzin, N.K. and Y.S. Lincoln. 2005. Methods of collecting and analyzing empirical materials. In The Sage handbook of qualitative research, eds Denzin, NK and Lincoln, YS, 641-49. Thousand Oaks, CA: Sage.

Fails, J.A., A. Druin and M.L. Guha. 2010. Mobile collaboration: Collaboratively reading and creating children's stories on mobile devices. In IDC 2010: Proceedings of the 9th International Conference on Interaction Design and Children, 20-9. Barcelona, Spain: ACM.

Fontana, A. and J.H. Frey. 2002. The interview: From neutral stance to political movement. In The sage handbook of qualitative research, eds Denzin, NK and Lincoln, YS, 695-727. Thousand Oaks: Sage.

Greenhow, C. and B. Robelia. 2009. Old communication. New literacies: Social network sites as social learning resources. Journal of Computer-Mediated Communication 14, no 4: 1130-61.

Halliday, M.A.K. 1978. Language as a social semiotic London: Edward Arnold.

Halliday, M.A.K. 1985. An introduction to functional grammar. London: Edward Arnold.

Hull, G. and M.E. Nelson. 2005. Locating the semiotic power of multimodality. Written Communication 22, no 2: 224-62.

Iedema, R.A. 2001. Analysing film and television: A social semiotic account of 'hospital: An unhealthy business. In Handbook of visual analysis, eds van Leeuwen, T and Jewitt, C, 183-206. London: Sage.

Jenkins, H., R. Purushotma, M. Weigel, K. Clinton and A.J. Robison. 2009. Confronting the challenges of participatory culture: Media education for the 21st century. Cambridge, Massachusetts: The MIT Press.

Jewitt, C. 2005. Multimodality, "reading", and "writing" for the 21st century. Discourse: Studies in the Cultural Politics of Education 26, no 3: 316-31.

Jewitt, C. 2006. Technology, literacy, learning: A multimodal approach. Oxon: Routledge.

Knobel, M. and C. Lankshear. 2007. A new literacies sampler: New literacies and digital epistemologies. New York: P. Lang.

Kress, G.R. 1997. Before writing: Rethinking paths to literacy. London: Routledge.

Kress, G.R. 2003. Literacy in the new media age. London: Routledge.

Kress, G.R. and T. van Leeuwen. 2006. Reading images : The grammar of visual design. 2nd ed. London: Routledge. 
Kukulska-Hulme, A. 2010. Learning cultures on the move: Where are we heading? Journal of Educational Technology \& Society 13, no 4: 4-14.

Lambert, J. 2002. Digital storytelling: Capturing lives, creating community. Berkley, CA: Digital Diner Press.

Lankshear, C. and C. Bigum. 1999. Literacies and new technologies in school settings. Pedagogy, Culture and Society 7, no 3: 445-65.

Lankshear, C. and M. Knobel. 2006. New literacies everyday practices and classroom learning. 2nd ed. Maidenhead \& New York: Open University Press.

Lankshear, C. and M. Knobel. 2008. Digital literacies : Concepts, policies and practices New literacies and digital epistemologies. New York: Peter Lang.

Laurillard, D. 2010. Foreword. In Researching mobile learning: Frameworks, tools and research designs, eds Vavoula, G, Pachler, N and Kukulska-Hulme, A, ix-xi. Oxford: Peter Lang.

Leu, D.J., L. Zawilinski, J. Castek, M. Banerjee, B.C. Housand, Y. Liu and M. O’Neil. 2007. What is new about the new literacies of online reading comprehension? In Secondary literacy: What education reveals about classroom practice, eds Rush, LS, Eakle, AJ and Berger, A, 37-68. Urbana, IL: National Council of Teachers of English,.

Liu, Y. and K.L. O'Halloran. 2009. Intersemiotic texture: Analyzing cohesive devices between language and images. Social Semiotics 19, no 4: 367-88.

Livingstone, S., E. van Couvering and N. Thumim. 2008. Converging traditions of research on media and information literacies: Disciplinary, critical and methodological issues In The handbook of research on new literacies, eds Coiro, J, Knobel, M, Lankshear, C and Leu, D, 103-32. Mahwah, NJ: Lawrence Erlbaum Associates.

Llamas, R.T. and W. Stofega. 2010. Worldwide smartphone 2010-2014 forecast update: December 2010. Framingham, MA: International Data Corporation.

Mackay, M.M. 2012. Australian mobile phone lifestyle index: AIMIA.

Martinec, R. 1998. Cohesion in action. Semiotica 120, no 1-2: 161-80.

Matthewman, S., A. Blight and C. Davies. 2004. What does multimodality mean for English? Creative tensions in teaching new texts and new literacies. Education, Communication \& Information 4, no 1: 153-76.

Meadows, D. 2003. Digital storytelling: Research-based practice in new media. Visual Communication 2, no 2: 189-93. 
Mills, K.A. 2010a. A review of the "digital turn" in the new literacy studies. Review of Educational Research 80, no 2: 246-71.

Mills, K.A. 2010b. Shrek meets Vygotsky: Rethinking adolescents' multimodal literacy practices in schools. Journal of Adolescent \& Adult Literacy 54, no 1: 35-45.

O'Toole, M. 1994. The language of displayed art. Cranbury, NJ: Routledge.

Pachler, N. 2010. Research methods in mobile and informal learning: Some issues. In Researching mobile learning: Frameworks, tools and research designs, eds Vavoula, G, Pachler, N and Kukulska-Hulme, A, 1-15. Oxford: Peter Lang.

Pachler, N., B. Bachmair and J. Cook. 2013. A socio-cultural ecological frame for mobile learning. In Handbook of mobile learning eds Berge, ZL and Muilenberg, LY, 35-46. New York: Routledge.

Pachler, N., B. Bachmair, J. Cook and G. Kress. 2010a. Mobile learning: Structures, agency, practices. 1st ed. New York: Springer.

Pachler, N., B. Bachmair, J. Cook and G. Kress. 2010b. A social semiotic analysis of mobile devices: Interrelations of technology and social habitus. In Mobile learning: Structures, agency, practices, 185-204. New York: Springer.

Pailliotet, A.W. and P.B. Mosenthal. 2000. Reconceptualising literacy in the age of media. New Jersey: JAI/Blex.

Reinking, D., M.C. Mckenna, L.D. Labbo and R.D. Kieffer. 1998. Handbook of literacy and technology. Mahwa, New Jersey: Lawrence Erlbaum Associates.

Richardson, L. 2000. Writing: A method of inquiry. In Handbook of qualitative research, eds Denzin, N and Lincoln, YS, 923-48. Thousand Oaks: Sage Publications.

Royce, T.D. 1998. Visual-verbal intersemiotic complementarity in the Economist magazine. PhD diss., University of Reading.

Royce, T.D. 2007. Intersemiotic complementarity: A framework for multimodal discourse analysis. In New directions in the analysis of multimodal discourse, eds Royce, TD and Bowcher, W, 63-109. New York: Lawrence Erlbaum \& Assoc.

Sheridan, M.P. and J. Roswell. 2010. Ed. Barton, D. Design literacies: Learning and innovation in the digital age. London: Routledge.

Spalter, A.M. and A. Van Dam. 2008. Digital visual literacy. Theory into Practice 47, no 2: 93-101. 
Spencer, S. 2011. Visual research methods : In the social sciences. 1st ed. New York, NY: Routledge.

Spires, H. and G. Morris. 2008. New media literacies, student generated content, and the YouTube aesthetic. In Proceedings of World Conference on Educational Multimedia, Hypermedia and Telecommunications 2008, eds Luca, J and Weippl, E, 4409-18. Chesapeake, VA: AACE.

Stivers, T. and J. Sidnell. 2005. Introduction: Multimodal interaction. Semiotica 156, no 1/4: $1-20$.

Techi. n.d. All of this now fits in your pocket. http:/www.techi.com/2012/05/all-ofthis-now-fits-in-your-pocket/.

Unsworth, L. 2006. Image/text relations and intersemiosis: Towards multimodal text description for multiliteracies education. Paper presented at the Proceedings of the 33rd International Systemic Functional Congress, in São Paulo, Brazil.

Unsworth, L. 2008a. Multiliteracies and metalanguage: Describing image/text relations as a resource for negotiating multimodal texts. In The handbook of research on new literacies, eds Coiro, J, Knobel, M, Lankshear, C and Leu, D, 377-405. Mahwah, NJ: Lawrence Erlbaum Associates.

Unsworth, L. 2008b. New literacies and the english curriculum : Multimodal perspectives. London; New York: Continuum.

van Leeuwen, T. 1999. Speech, music, sound. London: Macmillan.

van Leeuwen, T. 2005. Typographic meaning. Visual Communication 4, no 2: 137-43.

van Leeuwen, T., E. Djonov and K.L. O'halloran. 2012. "David Byrne really does love PowerPoint": Art as research on semiotics and semiotic technology. Social Semiotics (ahead-of-print): 1-15.

Vavoula, G., M. Sharples, P. Rudman, J. Meek and P. Lonsdale. 2009. Myartspace: Design and evaluation of support for learning with multimedia phones between classrooms and museums. Computers \& Education 53, no 2: 286-99.

Wolfe, S. and R. Flewitt. 2010. New technologies, new multimodal literacy practices and young children's metacognitive development. Cambridge Journal of Education 40, no 4: 387-99. 
Table 1. Page-based intersemiotic complementarity: IMAGE 1 and Paragraphs 1-2

IMAGE ORIENTATION: Naturalistic

\begin{tabular}{|c|c|c|c|c|c|c|}
\hline \multicolumn{2}{|c|}{ Participants } & \multirow{2}{*}{$\begin{array}{c}\text { Processes } \\
-\end{array}$} & \multirow{2}{*}{$\begin{array}{c}\text { Goals } \\
-\end{array}$} & \multicolumn{2}{|c|}{ Circumstances } & Attributes \\
\hline$S^{\prime} s$ & Playground & & & Morning & $\begin{array}{c}\text { Surrounded } \\
\text { by trees }\end{array}$ & Empty \\
\hline 1 & playground (R) & & & & & before the kids arrive (S) \\
\hline 2 & $\begin{array}{c}\text { bridge (M) } \\
\text { slippery dip (M) }\end{array}$ & & & & & \\
\hline 3 & & play (A) & & & & \\
\hline 4 & & $\begin{array}{c}\text { laughing (A) } \\
\text { distracted (A) } \\
\text { play (A) }\end{array}$ & & & & \\
\hline 5 & & & & & & \\
\hline 6 & & playing (A) & a game $(\mathrm{A})$ & & & \\
\hline
\end{tabular}


Table 2. Page-based intersemiotic complementarity: IMAGE 2 and Paragraph 3

IMAGE ORIENTATION: Naturalistic

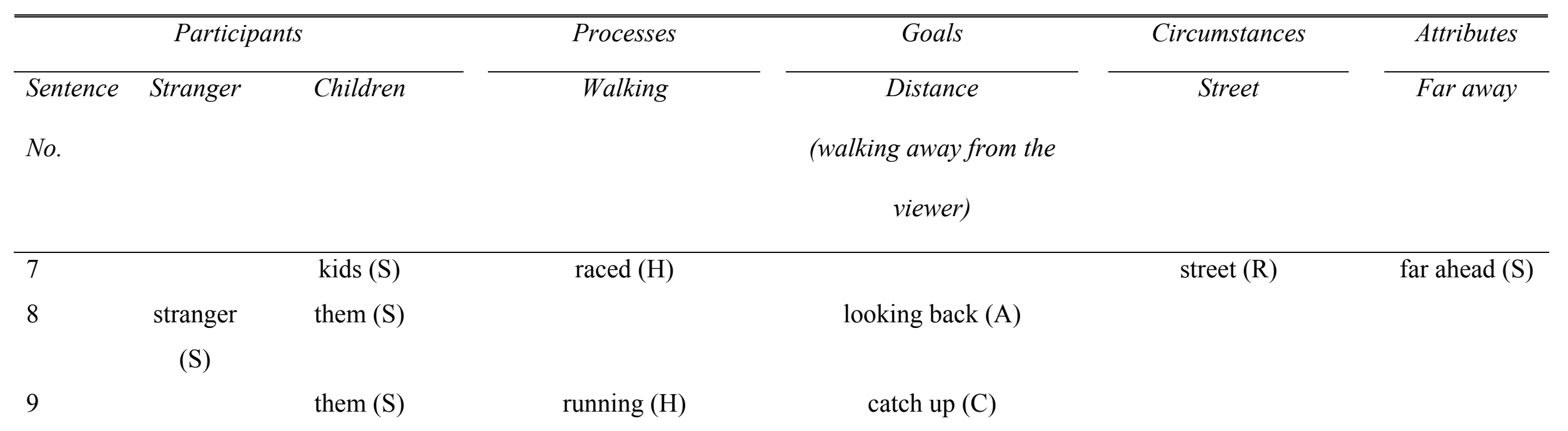


Figure 1. mStories website

Figure 2. This all fits in your pocket

Figure 3. "The Voice"

Figure 4. Power relations

Figure 5. Social proximity

Figure 6. Compositional

Figure 7. Compositional limitations 